\title{
Biografía, ¿para qué?
}

\author{
DANIELA SPENSER
}

a biografía no es un género de la historia que se practique en el ámbito académico mexicano. Ya sea porque se considera menor, híbrido o no del todo histórico, o porque se piensa que tiende a resaltar al individuo y hacer historia de bronce, hay pocos ejemplos que fusionen la investigación y el análisis rigurosos y contribuyan a crear nuevos saberes. La escritura de biografías fue minimizada cuando se adoptaron visiones totalizadoras que subsumieron al individuo a un todo teológico, político o social; cuando la cultura, como la revolucionaria dentro y fuera de México, la rebajó a una pieza en el mecanismo histórico de larga duración al quitar significado a las vidas de los individuos, salvo "como parte de una narrativa nacional, política, eclesiástica, histórica, que los englobaba y trascendía” (Krauze, 2013: 11; Sarlo, 2010: 149). Sin embargo, en años recientes ha habido un nuevo giro biográfico, en parte gracias a la revaloración de la dimensión subjetiva como uno de los componentes metodológicos para entender la historia.

En octubre de 2013, bajo los auspicios del Centro de Investigaciones y Estudios Superiores en Antropología Social y El Colegio Mexiquense, llevamos a cabo el congreso "Biografía, ¿para qué?" para examinar el estado de la cuestión de la biografía en México y po-

What Is the Use of Biography?

DANieLA SPEnSER Centro de Investigaciones y Estudios Superiores en Antropología Social-Distrito Federal,

Distrito Federal, México daniela.spenser@gmail.com

Desacatos 50, enero-abril 2016, pp. 10-11 ner a prueba las fronteras de su práctica académica. Con el título del congreso emulamos la convocatoria que, en ocasión del ordenamiento de documentos en el Archivo General de la Nación a finales de la década de 1970, reunió a historiadores y escritores para reflexionar sobre el sentido, las prácticas y los usos de la historia, sobre por qué y para qué se rescata, se ordena y se explica el pasado (Moreno, 1980: 7). Los eminentes historiadores y escritores que contribuyeron a responder la pregunta se centraron en el análisis y la explicación de los procesos históricos desde el poder y desde abajo, pero los individuos no figuraron en sus ensayos, salvo como entes inherentes a esos procesos.

En el congreso "Biografía, ¿para qué?” nos propusimos explorar los marcos metodológicos seleccionados para investigar, examinar y escribir la vida de los hombres y mujeres que elegimos. No se trataba 
del rescate de individuos que no figuraban en los anales de la historia ni de las grandes figuras, mucho menos queríamos defender la biografía como aquella historia que necesitaba legitimación. Recurrimos al género de la biografía porque éste permite un enfoque que articula al individuo con las fuerzas sociales que están más allá de su control y moldean su vida, así como su entorno. Partimos de la premisa de que la selección de un individuo puede servir de vehículo para explorar las tendencias sociales vividas subjetivamente por el sujeto, que añaden profundidad al contexto.

Los artículos incluidos en la sección temática de este número de Desacatos ilustran los enfoques y metodologías utilizados para reconstruir la vida de los individuos en sus respectivos contextos, a los que las biografías ayudan a comprender en un proceso de revaloración. El comentario a los artículos discute los alcances y las lagunas en la consecución de este cometido. $\mathbb{D}$

\section{Bibliografía}

Krauze, Enrique, 2013, “Prólogo”, en Mílada Bazant, Biografía. Modelos, métodos y enfoques, El Colegio Mexiquense, Zinacantepec, pp. 11-15. Moreno Toscano, Alejandra (ed.), 1980, Historia, ¿para qué?, Siglo XXI Editores, México.

Sarlo, Beatriz, 2010, Tiempo presente, notas sobre el cambio de una cultura, Siglo XXI Editores, Buenos Aires. 